\title{
The proper explanation of intuitionistic logic: on Brouwer's demonstration of the Bar Theorem
}

\author{
Göran Sundholm \\ Philosophical Institute, Leiden University, P.O. Box 2315, 2300 RA Leiden, The \\ Netherlands. goran.sundholm@gmail.com \\ Mark van Atten \\ SND (CNRS / Paris IV), I rue Victor Cousin, 75005 Paris, France. \\ vanattenmark@gmail.com \\ Der ... gefübrte Beweis scheint mir aber trotzdem \\ wegen der in seinem Gedankengange enthaltenen \\ Aussagen Interesse zu besitzen.
}

(Brouwer 1927B, n. 7)

Brouwer's demonstration of his Bar Theorem gives rise to provocative questions regarding the proper explanation of the logical connectives within intuitionistic and constructivist frameworks, respectively, and, more generally, regarding the role of logic within intuitionism. It is the purpose of the present note to discuss a number of these issues, both from an historical, as well as a systematic point of view.

\section{Background}

The Bar Theorem is a theorem in intuitionistic mathematics about trees. ${ }^{2} \mathrm{~A}$ bar is a set of nodes in a tree such that every infinite path through the tree intersects

I. 'The demonstration given ... nevertheless seems to me to be of interest, owing to the statements that are contained in its train of thought.'

2. Brouwer's reasoning has been carefully scrutinized in the literature, beginning with Kleene and Vesley 1965. We refer the reader to Dummett 1977, section 3.4, Martino and Giaretta I98I, Dummett 2000, section 3.4, and van Atten 2004, ch. 4. 
it; every infinite path is barred by that set of nodes. The question arises whether a bar admits of a direct, well-ordered construction. For the development of intuitionistic analysis it turns out to be crucial that such a well-ordered construction be possible. The content of the Bar Theorem is that this is indeed the case: it states that if a tree contains a bar, then it contains a well-ordered bar. ${ }^{3}$

Instantiated by a particular tree $t$, the Bar Theorem takes the form of the judgement: If $\mathrm{P}(\mathrm{t})$ has been demonstrated, then $\mathrm{Q}(\mathrm{t})$ is demonstrable. What is required for an intuitionistic demonstration of the Bar Theorem, then, is a method that transforms any demonstration ${ }^{4}$ that $\mathrm{P}(\mathrm{t})$ is true (the tree contains a decidable bar) into one that is $\mathrm{Q}(\mathrm{t})$ is true (the tree contains a well-ordered bar). Brouwer's demonstration depends on a general observation. Intuitionistically, to give a demonstration of a mathematical theorem is not to produce a certain linguistic object, but to produce a mental mathematical construction (or a method to obtain one, which method is of course also a mental mathematical construction) that makes the corresponding proposition true. Therefore, the requirement, for a demonstration that the consequence

$$
A \text { is true } \Rightarrow B \text { is true }
$$

holds, of a method that transforms any demonstration that $A$ is true into one that $B$ is true, is really the requirement of a method that transforms any mathematical construction that makes A true into one that makes B true. Any mathematical

3. As Kleene showed (Kleene and Vesley 1965, pp. 87-88), a condition is that the bar is decidable. Brouwer does not make this condition explicit, but in his proofs of 1924 (Brouwer $1924 \mathrm{D} 2$ ) and 1927 (Brouwer $1927 \mathrm{~B}$ ), it is satisfied, because there the bar is defined by an application of the continuity principle for choice sequences. The proof from 1954 (Brouwer 1954A), however, in which the bar is neither defined so as to be decidable, nor explicitly required to be, is incorrect. This seems to have been an oversight on Brouwer's part, rather than an overgeneralization, as the method he gives to construct the well-ordering depends on the decidability of the bar. See on this point also Veldman 2006.

4. Here we note and accept an ambiguity. In the primary sense, a demonstration is the act by and in which knowledge is acquired; this corresponds to Brouwer's 'Beweis'. But we also use 'demonstration' to translate Brouwer's 'Beweisführung', which is not an act but an object, namely the act objectified. 
means will do, and not just the ones that are so general as to correspond to logical laws. $^{5}$

Towards the end of his dissertation, Brouwer (1907, pp. 173-174) gave a lucid distinction between 'mathematical language' and 'mathematics of the second order' that in modern terms correspond to an 'object language' void of content and its (mathematical) study in a contentual 'meta-theory'. Brouwer told Hilbert about his conception during Hilbert's stay at Scheveningen in 1909 and, as he himself notes (Brouwer 1928A2, p. 375n. 2), it seems fair to regard this distinction as the (unacknowledged) source for Hilbert's metamathematics. Whether Hilbert ever read Brouwer's dissertation, or indeed any of Brouwer's writings on foundational matters, in a careful way, or at all, is a moot point; ${ }^{6}$ obviously the writings of Weyl were both his prime source of information concerning intuitionism, as well as his main bone of contention.

In the opposite direction, however, Brouwer read Hilbert's papers very carefully, and it may well be that Hilbert's lectures (Hilbert 1922; 1923) served as a direct source of inspiration for Brouwer's work on the Bar Theorem (Brouwer $1924 \mathrm{D} 2) .{ }^{7}$ Regarding the question of how to establish that a formal system is free from contradiction, Hilbert notes that

[d]er allgemeine Grundgedanke wie ein solcher Nachweis geschieht ist stets der folgende: wir nehmen an es liege ein Beweis konkret als Figur ... vor; ... Sodann zeigen wir durch eine inhaltlich finite Betrachtungsweise, daß dies kein unseren Anforderungen genügender Beweis sein kann.... Das Verfahren besteht darin, daß wir den als vorliegend angenommenen Beweis sukzessive abändern ... (Hilbert 1923, p. 157, our italics) ${ }^{8}$

5. Considered intuitionistically, logical theorems are nothing but very general mathematical theorems (Heyting 1931, p. 114; 1954, p. 78; 1956, p. 6).

6. Paul Bernays told Dirk van Dalen in 1977 that Hilbert had never even looked at Brouwer's writings: 'Er hat die Sachen überhaupt nicht gelesen' ('He has not read these things at all') (van Dalen 2005, p. 637).

7. We owe this suggestion to Per Martin-Löf. Already Heyting (1962, p. I04) notes that in Brouwer's work on the Bar Theorem, mathematical demonstrations are themselves considered as objects of mathematical study and in this way the method resembles Hilbert's.

8. 'The general line of thought as to how such a demonstration takes place is always the following: 
Brouwer's fullest account of the Bar Theorem uses the very same term vorliegen (Brouwer 1927 B, p. 63) with respect to a concrete demonstration that we have at hand. Also, his way of proceeding is very aptly described as 'performing successive changes on an assumed concrete proof', but now as a part of, not metamathematics, but mathematics. ${ }^{9}$ That Hilbert's work was an important source of inspiration for Brouwer gains further support from Brouwer's famous claim (1927B, p. 64n. 8) that some mathematical demonstrations are infinite mental constructions. It is expressly directed against Hilbert's metamathematics and, in fact, the possibly infinitary structure of a mathematical demonstration constituted his foremost argument against Hilbert. Whether, on the other hand, Hilbert's later incorporation of the infinitary 'omega-rule' (Hilbert 193ra,b) was a response to Brouwer's views on infinite proofs and his strictures against metamathematics, we cannot say.

A few years after Brouwer's work on the Bar Theorem, his student Arend Heyting contributed to the foundational debate in a two-fold way: first, he presented formal languages, as well as formalen Regeln (formal rules), for intuitionistic logic and mathematics (Heyting 1930a; 1930b; 1930c), and secondly, somewhat later, he provided a suitably constructive notion of proposition for intuitionism, by replacing the classical use of truth-conditions by 'proof-conditions', and gave concomitant meaning-explanations for the connectives and quantifiers of his formal languages (Heyting 1930d; 1931; 1934). The added precision was particularly welcome in the often confused debates on intuitionism: now also mathematicians and philosophers outside the intuitionistic fold could get a grasp of basic intuitionistic notions. From the vantage point of today, Brouwer's work on the Bar Theorem is often viewed in the light of Heyting's proof-explanations, and perhaps naturally so, but the temporal sequence was the opposite: Brouwer's work served as a major inspiration for Heyting. ${ }^{10}$ This decisive intuitionistic

we assume that a proof is at hand as a concrete figure ...; Then, from a finitist contentual point of view, we show that this cannot be a proof that meets our conditions. ... The procedure consists in performing successive changes on the assumed concrete proof ....'

9. See Heyting 1956, p. 45. From an intuitionistic point of view there is no special metamathematics.

Io. Brouwer applied the Proof Interpretation avant la lettre in a lecture on ordering from 1925; see 
contribution was not the only inspiration for Heyting's work, though. Formalism and logicism contributed in equal measure: formalism with the idea of a formal system (Heyting's system for propositional logic was in fact culled from Principia Mathematica, striking out constructively unacceptable propositions (van Atten 2005, p. 129)) and (late) logicism with the idea of systematic meaningexplanations after the fashion of the truth tables.

It is perhaps worth mentioning that Heyting's semantic work antedates that of Tarski (1935) by half a decade; it should be stressed though, that Heyting's work belongs to the pre-metamathematical period. The formal system is not a mere object of study, but a tool for gaining mathematical insights. ${ }^{11} \mathrm{His}$ formulae are meaningful propositions, rather than mere elements of a semiotisches Quadrupel as in Hermes 1938. Accordingly, for the variables in the system should be substituted only meaningful propositions (Heyting I930a, p. 3), and the turnstile serves as a Fregean assertion-sign, rather than as a Kleene-Rosser metamathematical theorem-predicate. ${ }^{12}$ In the light of the temporal mismatch and the encroachment of themes possibly alien to Brouwer's intuitionism, such as the use of (formal) languages and semantic meaning-explanations, caution is called for when applying the notions of Heyting to Brouwer's work.

Elsewhere we have dealt extensively with Heyting's constructive notion of a proposition and the matching meaning-explanations for the logical connectives, for instance van Atten 2004, ch. 2 and Sundholm 1983; 1997, and we see no need to repeat that discussion here. In particular, we assume familiarity with the general form of the BHK explanation of the logical constants.

van Dalen 2005, p. 676. In a personal communication, Dirk van Dalen told us that Heyting was probably not in the audience then, but that he very likely heard Brouwer make the remark on another occasion.

II. It is possible to divest the well-formed formulae of their content and study the objects thus obtained by mathematical means, as Heyting himself points out and also practised, with his Bernays-style independence proofs. But: '[D] iese Betrachtungsweise tritt für uns hinter die vorige [inhaltliche] zurück' ('This approach for us takes second place to the former [contentual] one.') See Heyting I930a, p. 43 and appendix.

I2. See Kleene 1952, pp. 88, 526. 
2 Brouwer's strategy: closure under rules versus truth of an implication

Gentzen's techniques of Natural Deduction have become very well known, and are now part of the standard logic curriculum both for philosophers and mathematicians. However, Brouwer's hypothesis in the demonstration of the Bar Theorem from an assumed proof is not of the familiar Natural Deduction kind, where a well-formed formula is put forward as an assumption and the derivation is continued by applying the rules of inference irrespective of whether the premises have been demonstrated or not. In the demonstration of the Bar Theorem, what is given is a concrete Beweisfübrung for the truth of the antecedent, and on this entity various transformation steps are performed in such a way that one obtains a demonstration also of the truth of the consequent. In Natural Deduction terms, Brouwer's assumption does not correspond to a customary 'assumption of A towards deriving B'. Instead, it is an assumption that one has a closed derivation of the antecedent formula $A$, that is, that formula $A$ is a derived theorem and that we possess its (closed) derivation. By performing suitable operations on this derivation we might obtain closed derivations for other theorems and have then established a 'closure property' of the system in question. Reflection on the easy proof of the Herbrand-Tarski Deduction Theorem for Hilbertstyle Propositional Calculus (HPC) may put the matter into proper relief. Here one is given a concrete derivation $D$ of the consequence $A, \Gamma \Rightarrow B$, whence $D$ is a finite tree with end-formula $\mathrm{B}$, with either (propositional) axioms, assumptions in $\Gamma$, or the assumption $A$, as top formulae, and further regulated by applications of Modus Ponens, that is, the sole derivation-rule in HPC. On this tree D one then performs an 'A $\supset$-transformation' by adding the sign-combination $A \supset$ in front of every formula that occurs in $\mathrm{D}$. This transformation obviously destroys inferential links and the rest of the demonstration consists in checking that the transformed tree $\mathrm{A} \supset$-D can be rebuilt into a derivation from assumptions in $\Gamma$ only that establishes the consequence $\Gamma \Rightarrow \mathrm{A} \supset \mathrm{B}$. Brouwer's reasoning makes use of a certain canonical form of the original Beweisfübrung and it is on the latter that the transformations are performed that yield a demonstration of the conclusion.

Note that it is only a closed proof-object a for proposition A (notation: a : 
$\operatorname{Proof}(\mathrm{A}))$ that can be evaluated to canonical form, the particular of which is determined by the meaning explanation of $A$; in a hypothetical judgement of the form $b: \operatorname{proof}(\mathrm{B})$ given that $\mathrm{x}: \operatorname{proof}(\mathrm{A})$, or in other notation, the conditional judgement

$$
\mathrm{x}: \operatorname{proof}(\mathrm{A}) \Rightarrow \mathrm{b}: \operatorname{proof}(\mathrm{B})
$$

neither $\mathrm{x}$ nor $\mathrm{b}$ admit such evaluation. In the first edition of his Elements of Intuitionism, Michael Dummett (1977, pp. I03, 400) has suggested that 'in order to exploit fully the intuitionistic meaning' of $\supset$ we need to be able to cite, for each statement $A$, an axiom of the form

\section{A $\supset$ there exists a proof of $A$ of such-and-such a kind}

'where a proof will be a suitable dressed spread, and the axiom will state restrictions on the form of the proof, depending upon the structure of the statement A'. But this is mistaken; as Dummett himself explains, in the second edition of Elements:

We cannot, however, hope to generate, for any but the simplest type of mathematical statement $A$, an axiom with antecedent $A$ and consequent an existential statement specifying the form a canonical proof of $A$ must take. We cannot do so because, if $A$ is a conditional or a universally quantified statement, we cannot circumscribe the effective operations that might serve as a proof of it. Such an operation might be recognized as efficacious only in the light of various known mathematical results, or of some intricate reasoning. (Dummett 2000, p. 273)

'Canonizability' does not apply to conditional constructions, but applies only to closed proof-objects. A given proof(-object) a of A can be evaluated to canonical form; to demand that this evaluation should take the form of a(n axiomatic or) 
demonstrable implication

$$
\mathrm{A} \supset \exists \mathrm{p}(\mathrm{p} \text { is a canonical proof of } \mathrm{A})
$$

asks too much. It asks too much, because it requires that the existence of a canonical proof can be obtained from A by the highly general means of logical inferences; whereas such a canonical proof may well depend on specific details of constructions for A, and in Brouwer's demonstration of the Bar Theorem this is indeed the case. ${ }^{13}$ In the case of the Deduction Theorem there is no need to perform a 'canonization' of the original derivation; Brouwer went from his given Beweisfübrung to one in canonical form, because his method of transformation needs control over the modes of inference that can occur in the deduction to which the transformation is applied. In the canonical form that is the case, since then the Beweisfübrung is built up from very basic inference steps only. This difference is due to the fact that in a formal system all the axioms and rules of inference are known from the outset. Brouwer, of course, does not establish the closure of any formal system; his transformations apply to real Beweisfübrungen and not to their simulacra in formal systems.

Thus what Brouwer demonstrates, is not the truth of the implication

$$
\mathrm{P}(\mathrm{t}) \supset \mathrm{Q}(\mathrm{t})
$$

13. Dummett's alleged axiom $\left({ }^{*}\right)$ from 1977 is closely related to his Principle K (Dummett 1976, p. 99): 'If a statement is true, then it must be in principle possible to know that it is true', as well as to the formula $\mathrm{p} \supset \diamond \mathrm{Kp}$ that plays a crucial role in the so-called Fitch's paradox. The matter is dealt with by Martin-Löf (1998) in considerable detail and for further discussion we refer to his treatment. The alleged axiom $\left({ }^{*}\right)$ also raises some other hard questions: what is the domain of quantification? If it is the whole 'universe of constructions', the worries concerning impredicativity come back with a vengeance. Furthermore, what is the status of the proofrelation? If it is a propositional function, over what domain? (The answer to this question would seem to take us back to the first worry.) And how, on pain of an infinite regress, can its meaning-explanation be cast in terms of proof-conditions using that very proof-relation itself? 
nor the holding of the equi-assertible consequence

$$
\mathrm{P}(\mathrm{t}) \text { is true } \Rightarrow \mathrm{Q}(\mathrm{t}) \text { is true }
$$

Instead, what is actually done in his reasoning is an attempt to demonstrate the closure of all of mathematics under the Bar Rule, that is, the rule

From the premise: $\mathrm{P}(\mathrm{t})$ is true, conclude: $\mathrm{Q}(\mathrm{t})$ is true $^{14}$

\section{Brouwer and the variety of proofs}

A quirk of the English language makes it extra difficult to treat of Brouwer's work in English: Brouwer's Germanic languages deploy Beweis (German) and bewijs (Dutch) and their cognates where today's mathematico-philosophical English uses proof. Proof stems from Latin probare whence, at least etymologically, proving and probing (testing) are quite close; demonstration is a more fitting translation of the terms used by Brouwer and in the sequel this will be adhered to. Clearly, for Brouwer the most important aspect of a mathematical demonstration is the deed, or act, whereby a theorem is established. This fits very well with one of the meanings offered by the Oxford English Dictionary:

3. a. The action or process of demonstrating or making evident by reasoning; the action of proving beyond the possibility of doubt by a process of argument or logical deduction or by practical proof; clear or indubitable proof; also (with pl.) an argument or series of propositions proving an asserted conclusion.

I4. Similar remarks can be made about the principle of Christian Charity: 'If a statement is true, then there is a moment $t$ at which the creating subject proves it'. As an implication this is highly problematic, but as a principle about demonstrations it is clear: given a demonstration by the subject of a statement, the subject can indicate the moment $t$ at which it arrived at that demonstration. 
In this primary sense the (act of) demonstration has only a limited endurance. After its completion it is no more and only the asserted theorem remains. What are called demonstrations, or proofs, in mathematical texts clearly are not acts; rather, they are blueprints for acts of demonstration and can be used by mathematicians for carrying out such acts. Brouwer famously spoke about demonstrations as mental constructions (1927 B, p. 64n. 8); this is ambiguous between, on the one hand, the demonstrative deed and, on the other, a mental objectification thereof, of which the written proof (demonstration) attempts a description. In connection with Brouwer's deviant rendering of the Law of Excluded Middle in the dissertation, Dirk van Dalen (1999, p. 106) has plausibly suggested that Brouwer was familiar with the traditional logic course given by Bellaar-Spruyt at Amsterdam, where a similar use can be found. Also his views on the act of demonstration, its mental products, and external linguistic signs, are strongly reminiscent of a scheme that is well known from traditional philosophy: ${ }^{15}$

The Traditional Structure of Logic:

\begin{tabular}{|c|c|c|c|}
\hline & $\begin{array}{c}\text { OpERATION OF THE } \\
\text { INTELLECT }\end{array}$ & (Mental) Product & (EXTERNAL) SigN \\
\hline I & Simple Apprebension & $\begin{array}{l}\text { Concept, Idea, } \\
\text { (Mental) Term }\end{array}$ & (Written/spoken) Term \\
\hline 2 & $\begin{array}{c}\text { Judging, } \\
\text { Composition/Division of } \\
\text { two terms }\end{array}$ & $\begin{array}{c}\text { Judgement, (Mental) } \\
\text { Proposition: } S \text { is } P \text {. }\end{array}$ & $\begin{array}{c}\text { Assertion, } \\
\text { (Written/spoken) } \\
\text { Proposition }\end{array}$ \\
\hline 3 & Reasoning, Inferring & (Mental) Inference & $\begin{array}{c}\text { (Written/spoken) } \\
\text { Inference, Reasoning }\end{array}$ \\
\hline
\end{tabular}

15. The diagram draws on a similar one in Maritain 1946, p. 6, but is reasonably standard. Maritain's source, and also that of virtually all other Neo-Thomists, is the splendid Ars Logica by John of St. Thomas. Bellaar-Spruyt's lectures (1903) had the traditional tripartite structure: Of terms; Of propositions; Of reasoning or syllogisms. 
$\mathrm{A}$ ( $\mathrm{n}$ act of $)$ demonstration is a mediate act pieced together out of several applications of Judging and Reasoning, with a matching (mental) product, and a written demonstration (proof) as external sign.

Brouwer's terminology in the original publications respects this scheme to a surprising extent. Thus, the title in the 1924 version of the Bar Theorem uses bewijs in Dutch (1924DI) and Beweis in German (1924D2), that is, demonstration, whereas for the mental entity to which the transformation is applied Brouwer uses Beweisfübrung in German in 1924 and 1927, and redeneering in Dutch (1924DI) in the spelling of the time, which latter term perhaps is best translated with reasoning. In his English presentations of the Bar Theorem, Brouwer (1954A; I98IA) uses the verb 'to prove'. However, at crucial places he deliberately seems to avoid the use of the noun 'proof. The term Beweisfübrung is rendered as 'constructive mathematical argument' and 'mathematical deduction', respectively. ${ }^{16}$

4 Heyting and the proof of implications

Reflection upon the construction $5+3$ shows that there is a fourfold sense of 'construction' involved here: ${ }^{17}$

I. the composite temporal act of generating the numbers 5 and 3 and then adding them together;

2. the object obtained as a product of this act, namely $5+3$;

3. the act objectified, as a description of the steps effected by the particular subject at a particular time; and

16. Traditional influence on Brouwer's thinking regarding logic and language is visible throughout his career and not only in the I920s. Thus, for instance, in 1947 he gave the following comment on his spread definition of I919: 'Because mathematics is independent of language, the word symbol (Zeichen) and in particular the words complex of digits (Ziffernkomplex) must be understood in this definition in the sense of mental symbols, consisting in previously obtained mathematical concepts.' (Brouwer 1947). Brouwer's views here are remarkably similar to certain medieval views on 'mental terms' due to William of Ockham, e.g., Ockham 1974, $\$ 3$, pp. 52-54.

17. We here draw upon Sundholm 1983 and Sundholm 1993. 
4. by abstracting of the objectified act with respect to subject and time, a prescription or blueprint for construction acts yielding $5+3$.

Heyting's semantical explanations are cast in terms of proof conditions. But:

Ein Beweis für eine Aussage ist eine mathematische Konstruktion, welche selbst wieder mathematisch betrachtet werden kann. (Heyting I93I, p. II 4$)^{18}$

Accordingly, propositions are regarded as conditions on constructions, where the relevant sense of construction is here that of 2 ; these constructions are the proof-objects that above we notated as 'a : $\operatorname{Proof}(\mathrm{A})$ '. This notion of proof at the level of propositional content, rather than that of asserted theorem, is novel with intuitionism. Complex conditions can be built up using dependency relations.

Of Heyting's clauses, only that for implication has proved controversial. There are two worries here. One is that Heyting's notion of implication appears to be impredicative, the other that it seems to require the introduction of hypothetical entities into intuitionistic mathematics (Griss).

The worry of impredicativity is that in an application of modus ponens, the proof construction for $\mathrm{A} \supset \mathrm{B}$ is applied to a proof construction for $\mathrm{A}$, which may itself use applications of modus ponens with antecedent $A$. This is readily accounted for by insisting that Heyting's clauses do not explain propositions in terms of any proofs, but only in terms of canonical proofs. Thus, a canonical proof for a conjunction $A \& B$ is an ordered pair $\langle a, b\rangle$ where $a$ is a (not necessarily canonical) proof for $\mathrm{A}$, and similar for $\mathrm{b}$. The sole condition on a non-canonical proof is that it be evaluable to a canonical one. Applying this insight to implication, we see that ultimately, no matter how a proof of $\mathrm{A}$ is given, it will have to be equal to a proof of $\mathrm{A}$ in canonical form, whence the impredicativity issue does not arise.

In natural deduction, a derivation commonly begins with assuming that a

I8. 'A proof for a proposition is a mathematical construction, which in turn can itself be considered mathematically.' 
proposition $\mathrm{A}$ is true. One then shows that under this assumption, certain propositions are also true, for instance $\mathrm{B}$, and may continue by concluding that the proposition $\mathrm{A} \supset \mathrm{B}$ is true outright, discharging the assumption that $\mathrm{A}$ is true. In terms of proof constructions, it might seem (and it did to Griss) as if we had to start this derivation by introducing a hypothetical construction for $\mathrm{A}$. This semblance, however, is spurious, as a careful analysis reveals that all constructions involved are actual.

Comparison with the case of function is illuminating. In the old sense, a function is an analytical expression in a variable, obtaining a value upon substitution of suitable arguments. For example, $x+2 \in \mathbb{N}$ given that $x \in \mathbb{N}$, as the following simple construction shows:

$$
\frac{x \in \mathbb{N}}{S_{x} \in \mathbb{N}}
$$

Conveniently summarizing, we may write $(x+2) \in \mathbb{N}(x \in \mathbb{N})$, as an expression of the relation of dependency. Functions in the old-fashioned sense are dependent objects of lowest level. Such dependent objects are not hypothetical, but enjoy a perfectly actual existence. A function in the modern sense of a mapping, that is, an independent object of higher level, is readily obtained from this by $\lambda$-abstraction: $\lambda x .(x+2) \in \mathbb{N} \rightarrow \mathbb{N}$.

In the premise of an application of implication-introduction, we have a proposition $B$ whose truth depends on that of $A$. In the light of the above, its proof object will be a dependent one of the form $b: \operatorname{Proof}(B)(x: \operatorname{Proof}(A))$. Moreover, this dependent object is actual and not hypothetical, which meets Griss' objection. From this, by implication-introduction, we readily obtain a suitable canonical proof-object for $\mathrm{A} \supset \mathrm{B}$ :

$$
\frac{\mathrm{b}: \operatorname{Proof}(\mathrm{B})(\mathrm{x}: \operatorname{Proof}(\mathrm{A}))}{\supset \mathrm{I}(\mathrm{A}, \mathrm{B}, \lambda \mathrm{x} \cdot \mathrm{b}): \operatorname{Proof}(\mathrm{A} \supset \mathrm{B})}
$$


Consequences are verified by functions in the old sense, whereas the canonical proof-object for an implication draws upon a function in the modern sense.

This way of elaborating the matter has been perfected in the constructive type theory of Per Martin-Löf (1994). Note that it generates the proof objects inductively, also for implication, thereby blocking impredicativity, and respects the parallel between canonical proofs and those of Gentzen introductory form. ${ }^{19}$

A proposition $\mathrm{A}$ is given in terms of a proof-condition $\operatorname{Proof}(\mathrm{A})$ that is explained in terms of how a canonical proof for A may be put together out of parts, depending on the structure and meaning of A. Propositional truth is explained in terms of proof-conditions: $\mathrm{A}$ is true $=_{\text {def }} \operatorname{Proof}(\mathrm{A})$ exists. This only defines the truth-conditions for $\mathrm{A}$; whether this condition is fulfillable, that is whether the proposition really is true, is of course not a matter of definition. This truth-condition may be fulfillable and then a proof-object can be found; the proposition can then be known to be true, whereas when it has been found the proposition is known to be true. The proof-condition for an implication $\mathrm{A} \supset \mathrm{B}$ requires a relation between the proof-conditions for the propositions $\mathrm{A}$ and $\mathrm{B}$; neither the condition itself nor its fulfillability presupposes any information concerning the fulfillability of the conditions for $\mathrm{A}$ and $\mathrm{B}$, that is, whether these propositions really are true. In order to understand, and even to know that an implication is true, it is only necessary to know the conditions for the truth of $\mathrm{A}$ and $\mathrm{B}$, but not whether these conditions are, or can be, fulfilled.

Brouwer was not overly concerned about implications where such knowledge is lacking. His referee report from around 1936 for Compositio Mathematica on the discussion between Freudenthal and Heyting ${ }^{20}$ contained merely this:

Interessante Diskussion über den Sinn der Implikation eines Satzes durch einen anderen, wenn über die Richtigkeit des letzteren Satzes nichts bekannt ist. ${ }^{21}$

19. As Michael Dummett observed, the usual kind of formulation, for instance 'A proof of $A \supset B$ is a method, or function, $f$, taking a proof $a: A$ into a proof $f(a): B$ ' does not respect this and is rather an elimination rule (Dummett 1994, pp. 32I-322).

20. Freudenthal 1936, Heyting 1936.

2I. 'Interesting discussion on the sense of one sentence being implied by another, when nothing is 
And in a later statement in 'Points and Spaces', one finds the likely reason for this brevity:

[T] he wording of a mathematical theorem has no sense unless it indicates the construction either of an actual mathematical entity or of an incompatibility (e.g., the identity of the empty two-ity with an empty unity) out of some constructional condition imposed on a hypothetical mathematical system. (Brouwer 1954A, p. 3 )

We read 'no sense' as 'no mathematical sense': the wording of the theorem may still make sense as a logical implication. Brouwer's point is that in that case, the implication is not directly informative about how things are, or are not, in the mathematical universe, and therefore is not descriptive of it. This brings us to our final theme.

\section{Ontological Descriptivism versus Meaning Theory}

With respect to ontology, intuitionism is a form of idealism: its denizens are mental constructions. However, this should not prevent us from seeing that epistemologically, it shares a realist stance with platonism: the correctness of a knowledge claim is in both cases ultimately reduced to matters of ontology, namely, in the intuitionistic case, to features of our mental constructions, and in the platonist case, to what states of affairs obtain in the platonist realm of mathematics. Both intuitionism and platonism therefore are versions of ontological descriptivism. In intuitionism, the ontology is idealist, in the sense that its objects are mental constructions, whereas in platonism the ontology is realist, in the sense that the objects are not of our making but self-subsistent.

This ontological descriptivism is clearly present in Brouwer, who attempts to exploit freely, without constraints, all four kinds of constructions (p. II above) for

known about the correctness of the latter sentence.' Brouwer Archive, Utrecht. Kolmogorov's lucid review in the Zentralblatt deserves to be better known; it also provides, in brief compass, a perfect illustration of the interpretative possibilities that we have been concerned to explore, whence we give it as an appendix. 
mathematical purposes. ${ }^{22}$ His demonstration of the Bar Theorem pivots around the issue of how to transform mathematical constructions. The properties of such transformations clearly depend on what kinds of constructions are being transformed.

In the meaning-theoretical tradition that started with Heyting and was continued by Martin-Löf making essential use of the Curry-Howard insight, so far only constructions of the second kind have played a role. It is difficult to see how that could be otherwise, in view of meaning-theoretical uniformity constraints.

One such constraint is that of compositionality. As we have noted above, Brouwer's Beweisfübrungen, that is, constructions of kind 3 or 4 , in natural deduction terms correspond to closed derivations, and thus an assumption that we possess such a Beweisfübrung amounts to an assumption not of A, but of $\vdash \mathrm{A}$. Such assumptions cannot take antecedent place in an implication, on pain of begging Geach's so-called 'Frege Point' (Geach 1965). This seems to put a tension on Arend Heyting: in his mathematical practice, he was undoubtedly a Brouwerian intuitionist, but in his semantical theorizing a constraint such as compositionality would seem to rule out accounting for that mathematical practice. ${ }^{23}$ From the vantage point of today, with the benefit of hindsight, these two different tendencies can be discerned within Heyting's work from the outset. Research after Heyting has commonly taken his views on proofs and propositions in a meaningtheoretical sense, and in the light of some of his formulations not unreasonably so. Thus Kreisel (1962, p. 198) wanted to 'give a formal semantic foundation for intuitionistic formal systems in terms of an abstract theory of constructions' by means of converting Heyting's informal explanations even into statable theorems. Prominent expositors of intuitionism, for instance Troelstra, Van Dalen,

22. For an ontological descriptivist justification of the weak continuity principle for choice sequences (exploiting aspects of constructions in sense $\mathrm{I}$ ), see van Atten and Dalen 2002 and van Atten 2007, ch. 7 .

23. See Sundholm 1985, section 3. Also Brouwer might have noticed this tension in Heyting: in the letter (July 17,1928 ) in which he suggests to Heyting to submit his formalization of intuitionistic logic and analysis to the Mathematische Annalen, he advises: 'En misschien zou zich ook (met het oog op \$13) het begrip “Gesetz” laten formaliseeren.' - 'And, with an eye on \$13, perhaps also the notion of "law”" can be formalized.' 
and Beeson, have continued this meaning-theoretical tendency, ${ }^{24}$ which from the early 1970s gained strength and cohesion from the Curry-Howard insight, as well as formal codification in the emerging constructive type theory of Per Martin-Löf. Support for this reading can be found in Heyting's early writings I930d (p. 958), I93I (p. II4), which jointly yield that the construction demanded by the proposition 'Euler's constant $\mathrm{C}$ is rational' is a pair $\langle\mathrm{a}, \mathrm{b}\rangle$ of natural numbers such that $\mathrm{C}=\mathrm{a} / \mathrm{b}$. Here, certainly, it is natural to view the construction demanded for the truth of a mathematical proposition as a mathematical object, rather than as a demonstration(-act or -trace). The demonstration that the proposition in question is true would consist in the production of a suitable construction-object. In later works, for instance Heyting 1960, p. I80, Heyting listed construction methods that square perfectly with the way proof-objects are built, namely (i) construction of a natural number; (ii) hypothetical construction; (iii) general method of construction; (iv) contradiction, and commented upon the use of these methods with great insight (Heyting 1958). Also Heyting's very early - in fact prior to their appearance in print - adoption (1935, pp. 78-79) of Gentzen's natural deduction methods, together with the Curry-Howard insight, serve to make the proof-object reading natural.

Of course, in the literature one finds routine references - no names, no packdrill! - to Heyting 1956, ch. 7 as a convenient source of the proof-explanations; it is therefore somewhat surprising to discover that these explanations cannot be found there. On the contrary, the explanations of logic are at the level of assertions and not at the level of propositions, e.g., p \& q can be asserted if and only if both $\mathrm{p}$ and $\mathrm{q}$ can be asserted. The justification of an asserted theorem is always via a demonstration: what we have here are assertion- and demonstrationconditions rather than proof-(object-)conditions. ${ }^{25}$

Another meaning-theoretical uniformity constraint is that of subject-inde-

24. Troelstra 1969, 2.I-2.3; van Dalen 1973, p. 2.I; Troelstra 1977, 2.I-2.2; Beeson 1985, II.4-II.6; Troelstra and Dalen 1988, 3.I-3.3.

25. Also formulations in the early expository text Grundlagenforschung seem to point in this direction, e.g., ' $[J]$ ede Aussage steht ... für die Intention auf eine mathematische Konstruktion die gewisse Bedingungen genügen soll. Ein Beweis für eine Aussage besteht in die Verwirklichung der in ihr geforderte Konstruktion.' (Heyting 1934, p. I4) - 'Every mathematical proposition stands for the intention towards a mathematical construction that should meet certain con- 
pendence. Constructions in sense $\mathrm{I}$ and 3 are subject-dependent, and it would therefore not seem possible to exploit them in meaning explanations that should be objectively valid. An ontological descriptivist who accepts a Husserlian notion of transcendental subjectivity can have it both ways: in that case, the relevant aspects of subjectivity in mathematics can be exploited in such a way that it gives the same result for all subjects. For a discussion of the matter, and a defense of the claim that Brouwer's notion of the subject is, as far as mathematics is concerned, indeed best understood as that of the transcendental subject in Husserl's sense, see van Atten 2004, ch. 6; for a discussion of intuitionism and intersubjectivity from a different perspective, see Placek $1999 .{ }^{26}$

In the meaning-theoretical tradition, the Bar Theorem so far has been proved only from the axiom of Bar Induction, whereas Brouwer's alternative demonstration has not been subsumed under that tradition's paradigm; on account of the above considerations on Beweisfübrungen, we suggest this is no coincidence. In this connection, one should observe however, that in the opposite direction it seems most likely that everything justifiable within the meaning-theoretical tradition would be accepted by Brouwer, ${ }^{27}$ with the likely exception of Ex Falso. ${ }^{28}$

ditions. A demonstration of a proposition consists in the actualization [realization] of the construction it demands.' Here the Verwirklichung clearly is an act. On the other hand, it is not said that this realization-act is the construction demanded, and hence an ambiguity remains. We leave the matter for a later occasion.

26. Husserl's influence on Heyting, via Becker, and more generally the influence of the phenomenological movement on Heyting, does not seem to have gone further than the (important) conception of a proposition as an expression of an intention, to be fulfilled by giving a demonstration (Heyting 1931). In particular, Heyting's later reflections on solipsism (Franchella 1995) do not draw on phenomenology. See also Franchella 2007.

27. One indication is the fact that Brouwer's reasoning for the equivalence of $\neg \mathrm{A}$ and $\neg \neg \neg \mathrm{A}$ (Brouwer ${ }_{1923} \mathrm{CI}$ ) is presented unconditionally; in particular, it is not ruled out that $\mathrm{A}$ has already been demonstrated.

28. Also in meaning-theoretical explanations, the grounds on which Ex Falso is accepted, if it is, are not quite of a kind with those that justify the other principles: in the former case, instead of providing a concrete transformation of conditions on constructions, one relies on the fact that constructions for $\perp$ are impossible. See van Atten 2008 for a careful examination of the issue and a defense of the view that Brouwer, for whom this distinction is important, does not accept Ex Falso. 
Brouwer also accepted the demonstration of the Bar Theorem from the axiom of Bar Induction, indeed it was he who proposed it, but he held that the alternative ontological descriptivist route taken in the main text of his paper from 1927 was of independent interest:

Intuitionistisch durchdacht, ist diese Versicherbarkeit nichts anderes als diejenige Eigenschaft, welche dadurch definiert ist, daß sie für jedes Element von $\mu_{\mathrm{I}}$ und für jedes Element von $\mu$ besteht, und daß sie für ein beliebiges $\mathrm{F}_{\mathrm{sn}_{\mathrm{r}} \ldots \mathrm{n}_{\mathrm{r}}}$ besteht, sobald sie für jedes $\nu$ für $\mathrm{F}_{\mathrm{sn}_{1} \ldots \mathrm{n}_{\mathrm{r}} \nu}$ erfüllt ist [formulation of Bar Induction]. Diese Bemerkung zieht die Wohlordnungseigenschaft eines beliebigen $\mathrm{F}_{\mathrm{sn}_{1} \ldots \mathrm{n}_{\mathrm{r}}}$ sofort nach sich. Der im Texte für die letztere Eigenschaft geführte Beweis scheint mir aber trotzdem wegen der in seinem Gedankengange enthaltenen Aussagen Interesse zu besitzen. (Brouwer 1927B, p. 63n. 7)

\section{Brouwer's Demonstration of the Bar Theorem as a Transcendental Argument}

We recall that for Brouwer, an argument for the Bar Theorem requires one to show that the consequent is demonstrable given that the antecedent has been demonstrated. We further saw that, on account of his ontological descriptivism, also specifically mental aspects of mathematical constructions may be exploited in building the required transformation method. And this, indeed, is the path his reasoning took. In acts of reflection, he observed what types of mental acts are available to us in constructing bars and determining their properties. On the basis of that (in effect, phenomenological) analysis, Brouwer claimed that any demonstration that a tree is barred, when analyzed into sufficient detail, can

29. 'When properly thought out intuitionistically, this securability is seen to be nothing but the property defined by the stipulation that it shall hold for every element of $\mu_{\mathrm{I}}$ and for every inhibited element of $\mu$, and that it shall hold for an arbitrary $\mathrm{F}_{\mathrm{sn}_{1} \ldots \mathrm{n}_{\mathrm{r}}}$ as soon as it is satisfied, for every $v$, for $\mathrm{F}_{s \mathrm{n}_{1} \ldots \mathrm{n}_{\mathrm{r}} v}$. This remark immediately implies the well-ordering property for an arbitrary $\mathrm{F}_{\mathrm{sn}_{1} \ldots \mathrm{n}_{\mathrm{r}}}$. The demonstration given in the text for the latter property nevertheless seems to me to be of interest, owing to the statements that are contained in its train of thought.' (van Heijenoort 1967, p. 46on. 7, modified) 
be decomposed into elementary mental steps that come in only a few different kinds. This analyzed demonstration Brouwer called the canonical form of the demonstration that the tree is barred. ${ }^{30}$ In effect, then, Brouwer's reflections led him to formulate a necessary condition: nothing can be a demonstration that a tree is barred unless it is analyzable into a mental demonstration of the specified canonical form. ${ }^{31}$ As we remarked above, the device of canonization serves to reduce the potentially great variety in demonstrations that the antecedent is true to the one specific structure of canonical demonstrations; and the specificity of this structure enabled Brouwer, in the second part of his demonstration of the Bar Theorem, to devise a construction method that transforms a canonical demonstration into a well-ordered construction of a bar.

That every demonstration of the antecedent can be rendered in such a simple and narrowly circumscribed canonical form is not proved by Brouwer but put forward as an insight or Thesis. As Heyting (1958, p. 342) noted, Church's Thesis is closely parallel to Brouwer's way of proceeding: also there we have the situation that a function is given with a calculation method. The Church-Turing thesis then says that the simple and narrowly defined rules for Turing machines can compute the function in question.

The first part of Brouwer's argument, then, has the following structure:

- I possess a demonstration that the tree is barred;

- (Insight or Thesis) It is a necessary condition of the possibility of possessing such a demonstration that it be analyzable into a mental demonstration of the specified canonical form;

- Therefore, the demonstration is analyzable into a mental demonstration

30. Or rather, 'a canonical form'; for Brouwer left open whether the canonical form that he proposed can be decomposed even further (Brouwer 1954A, p. 13). For his purposes it suffices to have just the one he suggests.

31. We stress that canonical in Brouwer's sense is not the same as cut-free or normal; a canonical demonstration may contain $\zeta$-inferences. In fact, the difference between the 1924 and 1927 versions of his demonstrations of the Bar Theorem is that in the former, all $\zeta$-inferences are eliminated, while in the 1927 presentation Brouwer realizes that for his purposes normalization with respect to $\zeta$-inferences is superfluous (Brouwer 1927 B, p. 65n. 9). 
of the specified canonical form.

As for Brouwer, to possess a demonstration is to have a certain mental experience, this argument is an instance of the following well-known type of transcendental argument:

- I have mental experience E;

- It is a necessary condition of the possibility of having mental experience E that $\mathrm{C}$;

- Therefore, C.

where the necessity invoked in the second premise is not merely logical or conceptual necessity.

We claim, therefore, that Brouwer's demonstration of the Bar Theorem is based on a transcendental argument. Brouwer nowhere uses the term 'transcendental' to characterize arguments, but he explicitly recognized the mechanism and its role in intuitionistic mathematics. In a late, prominent statement of his philosophical position from 1948 , he said:

[T] heorems holding in intuitionism, but not in classical mathematics, often originate from the circumstance that for mathematical entities belonging to a certain species, the possession of a certain property imposes a special character on their way of development from the basic intuition [i.e., on the way they are constructed in the mind], and that from this special character of their way of development from the basic intuition, properties ensue which for classical mathematics are false. A striking example is the intuitionist theorem that a full function of the unit continuum, i.e. a function assigning a real number to every non-negative real number not exceeding unity, is necessarily uniformly continuous. (Brouwer 1949 C, p. 1244$)^{32}$

32. Compare Brouwer 198IA, p. 94. 
The reference to the uniform continuity theorem of course is an implicit reference to the Bar Theorem as well, for Brouwer used the latter as a lemma for the former. One might of course wish to contest that the crucial claim at which Brouwer arrived by reflection on the mental is evident or at least correct. ${ }^{33}$ We do not propose to discuss the question of correctness here; what interests us here is the availability to Brouwer of this particular strategy. For Brouwer, it is quite natural to devise transcendental arguments in mathematics, because he is an ontological descriptivist for whom all mathematics is mental to begin with. In doing mathematics, this mental nature can often be left implicit, but one is free to exploit it.

For contrast, one may think of Leibniz. Leibniz held that, ontologically, the objects of geometry are objects in God's mind, but he also said that this ontological fact does not make it impossible for an atheist to be a geometer (Théodicée, \$184). What Leibniz seems to imply is that in doing geometry, the specifically ontological properties of the objects are of no interest. In particular, Leibniz nowhere suggests that the specifically ontological properties of mathematical objects can be exploited to demonstrate mathematical truths about them. However, it is not clear that for Leibniz that would have been impossible in principle.

Acknowledgement. We are grateful to Dirk van Dalen, Director of the Brouwer Archive, Utrecht, for permission to publish the items on page 14 and in footnote 23.

33. See, for example, Charles Parsons' remarks on p. 45 I of his introduction to Brouwer's 1927 paper in van Heijenoort 1967. 
Appendix: Kolmogorov's report on Freudenthal 1936 and Heyting 1936, $\mathrm{Zbl} 0015.24202$

Bekanntlich besteht vom intuitionistischen Standpunkte aus ein mathematischer B e we is immer in der Durchführung einer Konstruktion. Wird ein $S$ atz hypothetisch ohne Beweis ausgesprochen, so ist es vielmehr nur eine In t e $\mathrm{n} t$ i o $\mathrm{n}$ oder eine A u fg a be - die entsprechende Konstruktion zu finden. Fre ud en thal lehnt die Betrachtung solcher Intentionen, oder Aufgaben, ab und behauptet: Ein mathematischer Satz läßt sich nur mit seinem Beweis formulieren. Folglich kann man, nach F r e u $\mathrm{d}$ e $\mathrm{n} t \mathrm{~h}$ a $\mathrm{l}$, eine Implikation $\mathrm{a} \supset \mathrm{b}$ nur dann formulieren, wenn a schon bewiesen ist. Eine solche Deutung der Implikation ist, offenbar, praktisch inhaltslos. Fr e u d e n th a l versucht deswegen a $\supset$ b im Sinne des Prädikatenkalküls zu deuten. H e y t ing unterstreicht in seinen Bemerkungen die Notwendigkeit und Fruchtbarkeit, die Intentionen (oder Aufgaben) als Bestandteile einer Implikation zu betrachten. A. Kolmogoroff.

As is familiar, from the intuitionistic point of view a mathematical demonstration always consists in the execution of a construction. When a Satz [proposition, theorem] is stated hypothetically without demonstration, it is rather a mere intention or task - to find the corresponding construction. Freudenthal rejects the consideration of such intentions, or tasks, and claims: a mathematical Satz [proposition, theorem] can only be formulated with its Beweis [demonstration, proof]. Consequently, according to Freudenthal, one can only formulate an implication $\mathrm{a} \supset \mathrm{b}$ when a has already been demonstrated. Such an interpretation of the implication is, obviously, practically void of content. Freudenthal therefore attempts to interpret $\mathrm{a} \supset \mathrm{b}$ in the sense of the predicate calculus. In his remarks, Heyting emphasizes the necessity and fecundity of regarding intentions (or tasks) as components of an implication.

A. Kolmogorov.

\section{References}

Brouwer's writings are referred to according to the scheme in the bibliography van Dalen 2008.

van Atten, M. 2004. On Brouwer. Belmont: Wadsworth. 
van Atten, M. 2005. "Phenomenology's reception of Brouwer's choice sequences”. In Oskar Becker und die Philosophie der Mathematik. Ed. by V. Peckhaus. München: Wilhelm Fink Verlag, pp. IOI-II7.

- 2007. Brouwer Meets Husserl. On the Phenomenology of Choice Sequences. Dordrecht: Springer.

- 2008. Luitzen Egbertus Jan Brouwer. In Zalta 1997-, Winter 2008. http:// plato.stanford.edu/archives/win20o8/entries/brouwer.

van Atten, M. and D. van Dalen 2002. "Arguments for the continuity principle”. Bulletin of Symbolic Logic 8(3), pp. 329-347.

Beeson, M. 1985. Foundations of Constructive Mathematics. Heidelberg: Springer.

Bellaar-Spruyt, C. 1903. Leerboek der Formeele Logica. bewerkt naar de Dictaten van wijlen Prof.Dr. C.B. Spruyt door M. Honigh. Haarlem: Vincent Loosjes.

Benacerraf, P. and H. Putnam, eds. 1983. Philosophy of Mathematics. Selected Readings. 2nd ed. Cambridge: Cambridge University Press.

Brouwer, L.E.J. 1907. Over de grondslagen der wiskunde. $\mathrm{PhD}$ thesis. Universiteit van Amsterdam. English translation in Brouwer 1975, II-IOI.

- 1923 CI. "Intuitionistische splitsing van mathematische grondbegrippen". KNAW Verslagen 32. English translation Mancosu 1998, pp. 286-289, pp. 87788 o.

- 1924Di. "Bewijs dat iedere volle functie gelijkmatig continu is". KNAW Verslagen 33, pp. 189-193. English translation in Mancosu 1998, 36-39.

- 1924D2. "Beweis dass jede volle Funktion gleichmässig stetig ist". KN $A W$ Verslagen 27, pp. 189-193. Facsimile reprint in Brouwer 1975, 286-290.

- 1927B. "Über Definitionsbereiche von Funktionen”. Mathematische Annalen 97, pp. 60-75. Facsimile reprint in Brouwer 1975, 390-405. English translation of sections I-3 in van Heijenoort $1967,457-463$.

- I928A2. "Intuitionistische Betrachtungen über den Formalismus". KN $A W$ Proceedings 31, pp. 374-379. Facsimile reprint in Brouwer 1975, 409-414. English translation in Mancosu 1998, 40-44.

- 1947. "Richtlijnen der intuïtionistische wiskunde". Indagationes Mathematicae 9. English translation Brouwer 1975, p. 477, p. 197. 
Brouwer, L.E.J. 1949 C. "Consciousness, philosophy and mathematics". In Proceedings of the 1oth International Congress of Philosophy, Amsterdam 1948. Ed. by E. Beth, H. Pos, and J. Hollak. Vol. 2.I. Facsimile reprint in Brouwer 1975, 480-494.

- 1954A. "Points and spaces". Canadian Journal of Mathematics 6, pp. I-I7. Facsimile reprint in Brouwer 1975, 522-538.

- 1975. Collected Works. Vol. I: Philosophy and Foundations of Mathematics. Ed. by Arend Heyting. Amsterdam: North-Holland.

- 198IA. Brouwer's Cambridge Lectures on Intuitionism. Ed. by Dirk van Dalen. Cambridge: Cambridge University Press.

van Dalen, D. 1973. "Lectures on intuitionism”. In Cambridge Summer School in Mathematical Logic 197I. Ed. by H. Rodgers and A.R.D. Mathias. Vol. 337. Lecture Notes in Mathematics. Heidelberg: Springer, pp. I-94.

- 1999. Mystic, Geometer, and Intuitionist. The Life of L.E.J. Brouwer. Vol. I: The Dawning Revolution. Oxford: Clarendon Press.

- 2005. Mystic, Geometer, and Intuitionist. The Life of L.E.J. Brouwer. Vol. 2: Hope and Disillusion. Oxford: Clarendon Press.

- 2008. “A bibliography of L.E.J. Brouwer”. In One Hundred Years of Intuitionism. The Cerisy Conference. Ed. by Mark van Atten, Pascal Boldini, Michel Bourdeau, and Gerhard Heinzmann. Basel: Birkhäuser, pp. 343-39o.

Dummett, M. 1976. "What is a theory of meaning?" II. In Truth and Meaning. Ed. by G. Evans and J. McDowell. Oxford: Clarendon Press, pp. 67-I37.

- 1977. Elements of Intuitionism. Oxford: Oxford University Press.

- 1994. "Reply to Sundholm". In The Philosophy of Michael Dummett. Ed. by B. McGuinness and G. Oliveri. Dordrecht: Kluwer, pp. 318-328.

- 200o. Elements of Intuitionism. 2nd edition. Oxford: Clarendon Press.

Ewald, W. 1996. From Kant to Hilbert. Readings in the Foundations of Mathematics, 2 vols. Oxford: Oxford University Press.

Franchella, M. 1995. "Like a bee on a window pane: Heyting's reflections on solipsism”. Synthese I05(2), pp. 207-25I.

- 2007. "Arend Heyting and phenomenology: is the meeting feasible?" Bulletin d'Analyse Phénoménologique 3(2). Available online at http://popups.ulg.ac. be/bap/document.php?id=I47, pp. I-2I. 
Freudenthal, H. 1936. "Zur intuitionistischen Deutung logischer Formeln”. Compositio Mathematica 4, pp. II2-II6.

Geach, P. 1965. "Assertion". Philosophical Review 74(4), pp. 449-465.

van Heijenoort, J., ed. 1967. From Frege to Gödel. A Sourcebook in Mathematical Logic, I879-193I. Cambridge MA: Harvard University Press.

Hermes, H. 1938. Semiotik. Eine Theorie der Zeichengestalten als Grundlage für Untersuchungen von formalisierten Sprachen. Leipzig: Hirzel.

Heyting, A. 1930a. "Die formalen Regeln der intuitionistischen Logik". I. Sitzungsberichte der Preussischen Akademie der Wissenschaften, pp. 42-56. English translation in Mancosu 1998, 3II-327.

- 1930b. "Die formalen Regeln der intuitionistischen Logik". II. Sitzungsberichte der Preussischen Akademie der Wissenschaften, pp. 57-6I.

- 1930c. "Die formalen Regeln der intuitionistischen Logik". III. Sitzungsberichte der Preussischen Akademie der Wissenschaften, pp. 158-169.

- r93od. "Sur la logique intuitionniste". Académie Royale de Belgique, Bulletin de la Classe des Sciences 16. English translation Mancosu 1998, pp. 306-310, pp. $957-963$.

- 1931. "Die intuitionistische Grundlegung der Mathematik". Erkenntnis 2, pp. I06-II5. English translation in Benacerraf and Putnam 1983, 52-6I.

- 1934. Mathematische Grundlagenforschung, Intuitionismus, Beweistheorie. Berlin: Springer.

- 1935. "Intuïtionistische wiskunde". Mathematica B 4, pp. 72-83.

- 1936. "Bemerkungen zu dem Aufsatz von Herrn Freudenthal 'Zur intuitionistischen Deutung logischer Formeln”". Compositio Mathematica 4, pp. II7II8.

- 1954. "Logique et intuitionnisme". In Applications scientifiques de la logique mathématique. (Actes du ${ }^{e}$ colloque internationale de logique mathématique, Paris, 1952). Paris: Gauthier-Villars.

- 1956. Intuitionism. An Introduction. Amsterdam: North-Holland.

- 1958. "Blick von der intuitionistischen Warte". Dialectica I2, pp. 332-345.

- 1960. "Remarques sur le constructivisme". Logique et Analyse 3, pp. 177-182. 
Heyting, A. 1962. "Méthodes et problèmes de l'intuitionnisme”. In Actes du colloque de mathématiques réuni à Clermont à l'occasion du tricentenaire de la mort de Blaise Pascal. Tome I. Introduction et logique mathématique. Faculté des Sciences de l'Université de Clermont, pp. IOI-IO5.

Hilbert, D. 1922. "Neubegründung der Mathematik (Erste Mitteilung)". Abhandlungen aus dem Mathematischen Seminar der Hamburgischen Universität I, pp. 157-177. English translation in Mancosu 1998, 198-214.

- 1923. "Die logischen Grundlagen der Mathematik". Mathematische Annalen 88. English translation Ewald 1996, pp. II34-II48, pp. I5I-165.

- 1931. "Beweis des Tertium non datur". Nachrichten von der Gesellschaft der Wissenschaften zu Göttingen, Math.-Phys. Klasse I(22), pp. I20-I25.

- 1931. "Die Grundlegung der elementaren Zahlenlehre". Mathematische Annalen I04, pp. 485-494.

Kleene, S. 1952. Introduction to Metamathematics. Amsterdam: North-Holland.

Kleene, S. and R. Vesley 1965. The Foundations of Intuitionistic Mathematics, Especially in Relation to Recursive Functions. Amsterdam: North-Holland.

Kreisel, G. 1962. "Foundations of intuitionistic logic". In Logic, Methodology and Philosophy of Science, Proc. Ig6o Int. Congr. Ed. by E. Nagel, P. Suppes, and A. Tarski. Stanford: Stanford University Press, pp. 198-210.

Mancosu, P., ed. 1998. From Brouwer to Hilbert. The Debate on the Foundations of Mathematics in the 1920s. Oxford: Oxford University Press.

Maritain, J. 1946. An Introduction to Logic. London: Sheed and Ward.

Martin-Löf, P. 1994. "Analytic and syntheticjudgement in type theory”. In Kant and Contemporary Epistemology. Ed. by P. Parini. Dordrecht: Kluwer, pp. 8799.

- 1998. "Truth and knowability: on the principles C and K of Michael Dummett". In Truth in Mathematics. Ed. by H. Dales and G. Oliveri. Oxford: Clarendon Press, pp. IO5-II4.

Martino, E. and P. Giaretta 198I. "Brouwer, Dummett, and the Bar Theorem". In Atti del Congresso Nazionale di Logica, Montecatini Terme, I-s Ottobre 1979. Napoli.

Ockham, W. 1974. Ockham's Theory of Terms. Part I of the Summa Logicae (trl. M. Loux). Notre Dame: University of Notre Dame Press. 
Placek, Tomasz 1999. Mathematical Intuitionism and Intersubjectivity. A Critical Exposition of Arguments for Intuitionism. Dordrecht: Kluwer.

Sundholm, G. 1983. "Constructions, proofs and the meaning of logical constants”. Journal of Philosophical Logic 12(2), pp. 151-172.

- 1985. "Brouwer's anticipation of the principle of charity". Proceedings of the Aristotelian Society LXXXV, pp. i-xiv.

- 1993. "Questions of proof”. Manuscrito XVI(2), pp. 47-70.

- 1997. "Implicit epistemic aspects of constructive logic". Journal of Logic, Language and Information 6, pp. 191-212.

Tarski, A. 1935. “Der Wahrheitsbegriff in den formalisierten Sprachen”. Studia Philosophica I, pp. 26I-405.

Troelstra, A. 1969. Principles of Intuitionism. Vol. 95. Lecture Notes in Mathematics. Berlin: Springer.

- 1977. Choice Sequences. A Chapter of Intuitionistic Mathematics. Oxford: Oxford University Press.

Troelstra, A. and D. van Dalen 1988. Constructivism in Mathematics. An Introduction. 2 vols. Amsterdam: North-Holland.

Veldman, W. 2006. "Brouwer's real thesis on bars". Philosophia Scientiae, Cabier Spécial 6, pp. 21-42.

Zalta, E., ed. 1997-. The Stanford Encyclopedia of Philosophy. http:// plato. stanford.edu. 